\title{
The geography of pastoral mobility: A spatio-temporal analysis of GPS data from Sahelian Senegal
}

\author{
Hanne Kirstine Adriansen ${ }^{1, *} \&$ Thomas Theis Nielsen ${ }^{2}$ \\ ${ }^{1}$ Danish Institute for International Studies, Strandgade 56, 1401, Copenhagen K, Denmark; ${ }^{2}$ Institute of Geography, \\ University of Copenhagen, Oester Voldgade 10, 1350, Copenhagen K, Denmark; *Author for correspondence (Tel.: \\ +45 3269 8722; Fax: +45 3269 8700; E-mail: hka@diis.dk)
}

Key words: GPS data, pastoral mobility, Senegal, spatial analysis

\begin{abstract}
The aim of this paper is to show the contribution of geography to the study of pastoral mobility. While pastoralists of Ferlo, Senegal, have become semi-sedentary, little is known about the mobility of their livestock. In this paper, pastoral mobility is analysed using GPS measurements of cattle movements made by a pastoralist from 1997 to 2000. Based on data from 3 years, a quantification of the extent of movements and mappings of the patterns are made. The results show that cattle walk about $5000 \mathrm{~km}$ on an annual basis, and while a great deal of the mobility can be characterised as daily circular movements between the camp and watering points, occasional transhumance is still used to make the most of variable resources.
\end{abstract}

\section{Introduction}

Pastoralists' movements of their herds in the landscape touch upon the relationship between people and nature through the use of space. Issues such as the construction of space and human-nature relationship have gained increasing attention within human geography in recent years (see e.g. Lane, 2001; Fitzsimmons, 2004). Many of these contributions draw upon 'abstract' understandings of space and they have paid attention to the formation of space into place (e.g. Taylor, 1999; Unwin, 2000; Smith, 2004). While sympathizing with these understandings, the present paper addresses pastoralists' use of the physical space constituted by the natural resources of importance for their livestock. This paper is a continuation of studies such as Bernus (1979) arguing that mobility is a rational exploitation of the Sahelian pastoral milieu taking into account the discontinuities of natural resources in space and time. Hence, we do not elaborate or discuss spatial mobility as a political mechanism (Irons, 1968; Burnham, 1979). Rather, the purpose of the paper is methodological; it is to illustrate how GPS can be used for mapping and quantifying pastoral mobility and illustrate the potential of using this in combination with other spatial data. In the paper, we pay attention to the practical problems associated with using GPS for studying pastoral mobility. In other words, the paper outlines the contribution of geography in understanding pastoral mobility. In doing so, we acknowledge the contribution from ecology, understanding vegetation dynamics, and from anthropology, analysing socio-cultural explanations for mobility. Some of these thoughts will be briefly outlined.

Within ecology the 'new rangeland paradigm' (e.g. Ellis and Swift 1988; Behnke et al., 1993), which emerged in the early 1990s has changed the understanding of pastoral mobility. Now mobility is regarded a flexible strategy that balances the variability in natural resources in arid and semi-arid areas (Niamir-Fuller, 1998; Thébaud and Batterbury, 2001). Although it has been debated if mobility should be considered a means to obtain risk aversion or as a feature of 'high reliability systems' (Roe et al. 1998), mobility is regarded as integral to pastoral management (Pamo, 1998). While this perception of mobility is relatively new among dryland ecologists, this is not a new line of thought among many anthropologists studying pastoralists (e.g. Stenning, 1957; Dyson-Hudson and Dyson-Hudson, 1980).

While many scholars have studied and mapped pastoral mobility in West Africa (e.g. Basset, 1986; Dupire, 1975), few studies have tried to quantify pastoral mobility using contemporary technology and to understand the spatio-temporal dynamics of livestock movements. Studies of pastoral mobility have been dominated by coarse scale spatio-temporal investigations (e.g., Stenning, 1957; Johnson, 1969; Basset, 1986; Niamir-Fuller, 1999). Moreover, mobility is often perceived from the family-unit point of view and many studies do not consider mobility of animals a separate entity. There are exceptions; Coppolillo's study of pastoral herds in Tanzania is one of them. The author developed a model of herding in order to identify and 
assess grazing impact (Coppolillo, 2000). The technological development has enabled more accurate studies and in 2002, Turner and Hiernaux called for precise quantitative studies of pastoral mobility (Turner and Hiernaux, 2002). The use of GPS for mapping and quantifying herd location in time and space across the pastoral landscape seems like an obvious solution to this call. However, only few studies have been made so far (examples being Schareika, 2001, Schlecht et al., 2004; Sickel, 2004).

\section{The study area}

This paper is based on a study carried out in the Ferlo region of northern Senegal. Ferlo is located in the Sahelian zone. The climate is characterised by a short, relatively well-defined rainy season, where the largest precipitation occurs in July, August, and September. Hot, dry periods occur before and after the rainy season in April-June and October-November. DecemberMarch is a cool, dry period. The north-south rainfall gradient is approximately $1 \mathrm{~mm} / \mathrm{km}$, and the mean annual rainfall for the period 1986-1996 was approximately $200 \mathrm{~mm}$ in the north and $400 \mathrm{~mm}$ in the south. The coefficient of variation in annual precipitation is above 33 percent, which means that the long term performance of the ecosystem is better understood in terms of dis-equilibrium dynamics than by measures of mean values (Ellis et al., 1993; Ellis, 1995).

In the area sandy soils prevail and ancient longitudinal dunes dominate the topography. The distribution of vegetation is related to soil and geomorphologic characteristics: to the north-west, vegetation can be described as bushed grassland, with a woody cover seldom exceeding 5 percent and more typically around 2 percent. Towards the south, this percentage increases to 5-20 percent. Annuals dominate the herbaceous layer, particularly in the north. Species such as Schoenefeldia gracilis, Cenchrus biflorus and Zornia glochidiata dominate, yet the abundance of these species changes from year to year and from place to place, depending on rainfall, especially rainfall patterns in the early rainy season, and on grazing pressure.

The majority of the inhabitants are Fulani pastoralists, who own cattle, sheep, and goats (for further description of pastoralists and the evolution of grazing systems in Ferlo see e.g. Barral, 1982; Santoire 1983; Ba, 1986; Grenier, 1987; Juul, 1999). Historically, the rangelands of Ferlo served as a grazing area for pastoralists, who had to pursue large-scale migration due to the lack of permanent water supplies in the area. Pasture was abundant, but as temporary water holes dried out during the dry season, pastoralists moved north to the Senegalese river valley or south and west to the so-called peanut basin (Freudenberger and Freudenberger, 1993). In the 1950s, the French colonial administration made the first boreholes equipped with motor pumps in Ferlo, which meant that the area could be used on a permanent basis. The possibility of staying in the area during the dry season meant that people became semi-sedentary, creating a permanent rainy-season camp. Some pastoralists took up rain-fed agriculture, especially in the southern part of the area with the highest rainfall amounts. More boreholes were established and villages grew around them (Juul, 1999). Since the great drought of 1973, there has been a decrease in the annual precipitation (Equipe ECOSSEN, 1997), which means that many pastoralists abandoned cultivation as they find it unprofitable. Only a small percentage of the area is cultivated today and the cultivating pastoralists fence their fields in order to avoid trespassing of livestock. Crop-livestock interactions such as exchange of manure and crop-residuals are not significant, as most cultivators also own animals themselves (Adriansen, 2006). The construction of boreholes has therefore changed the strategies employed by the pastoralists and also the use of mobility. The pastoralists now employ what Barral (1982) has called 'micro-nomadism', staying in vicinity of their rainy season camp. Depending on the progression of the dry season, the herd composition, and the preferences of the household, they may stay either in the camp or move around after the rainy season. The semisedentary lifestyle and the lack of predators mean that the cattle can be left to roam freely (Touré, 1990). Hence, many pastoralists choose not to herd their cattle full-time when they are in an area that the cattle know, and instead guide the cattle in the right direction in the morning and count the cattle at the watering point in the middle of the day. Small ruminants, on the other hand, are still herded, because otherwise these can get lost, stolen, or eaten by jackals.

Ferlo has been divided into resource management units following the boreholes; these are called pastoral units (unité pastorales). Today, water is supplied from three sources: temporary water holes (ponds), boreholes, and pipes extending from these, called antennas. The ponds can be used free of charge, while the pastoralists have to pay a fee for water from the borehole and antennas (Alissoutin, 1997). The boreholes are usually closed until the ponds dry out. Mobility patterns therefore change in accordance with the drying out of ponds.

Fieldwork was carried out in the area from October 1997 till November 2000. The household of Birame Nguesa Ka, who lives in a camp called Belel Nelbi with his extended family, was the primary study unit. Belel Nelbi is located in a pastoral unit called Thiel approximately $12 \mathrm{~km}$ from a borehole and $7.5 \mathrm{~km}$ from an antenna. The cattle and the small ruminants have different mobility patterns. As Birame was not involved in herding the small ruminants, it was only possible to measure the mobility of the cattle. Birame was given a GPS and hired to follow the cattle and take GPS measurements one day every week. Furthermore, Birame was asked to take notes for every measurement, describing the time and location (e.g. a borehole or a pond) of the measurement. These notes were used in 
combination with the spatial information from the GIS on location of ponds, etc. Apart from the work made by Birame, we conducted questionnaires, qualitative interviews, and participatory observations in Belel Nelbi. This information has been used to make informed interpretations of GPS data and the decision making visà-vis mobility. Although Birame acts as a 'president' for the pastoral unit of Thiel, his household can be characterised as typical in terms of labour availability, herd size, and use of pastoral mobility. Thus, his status in the community does not affect on the household's assets or their way of life. This is typical of households in the area.

\section{Methodology}

Four sources of data were available for this study: a GIS of the pastoral unit produced and kindly made available by the Centre de Suivi Ecologique in Dakar (CSE), monthly satellite-derived estimates of rain intensity, weekly GPS measurements of cattle mobility carried out by Birame, and interviews, observations, etc. made in Birame's household, Belel Nelbi.

The following GIS parameters were utilized in the analysis:

1. The area and spatial division of the pastoral unit (into eight 'sectors').

2. The location of Belel Nelbi (Birame's camp).

3. The location of water outlets (boreholes and 'antennas') as well as ponds.

Since no ground-measured precipitation data were available for the study area during the investigated period, alternative indications of precipitation were required. For this purpose satellite-derived precipitation estimates were obtained from the Global Precipitation Climatology Project (GPCP, 2001). These data are monthly mean rainfall estimates with a spatial resolution of 1 degree for the investigated period. Since no single satellite data source covers the entire data record, the GPCP data comprise several different satellite sensors and are calibrated using about 6700 ground rain gauge stations. Some problems and shortcomings of this data source in relation to the present study can be identified:

First, data are distributed in a 1 degree grid. This corresponds to approximately $110 \mathrm{~km}$, which is a very coarse scale in relation to the mobility patterns investigated. Furthermore, the location of the study area with associated mobility patterns was found to be in the centre of 4 different pixels. Thus, the total area covered by the 4 pixels spans from the edge of the Sahara in the north well into the savannah of central Senegal, as illustrated in Figure 1. As mentioned, there is a marked rainfall gradient from the North to the South of approximately $1 \mathrm{~mm}$ per kilometre. This in turn indicates that the area covered by the four pixels potentially contains large local differences that cannot be expected to be discernable in the precipitation data.

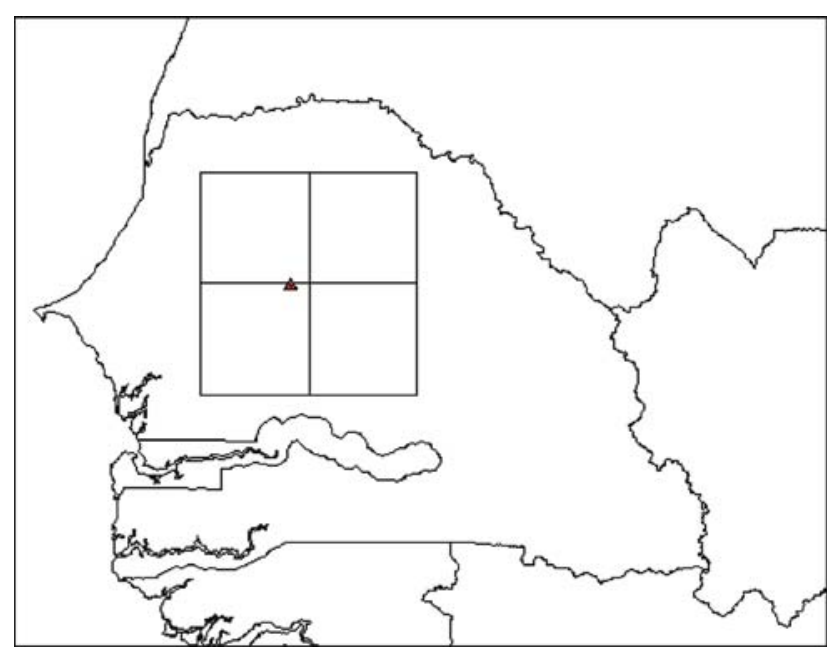

Figure 1. Map of Senegal showing the location of the GPCP pixels and the location of Belel Nelbi.

Another shortcoming is that the data do not contain information about specific rainfall events but are average rainfall intensity estimates for 30 days. This implies that differences in the temporal occurrence of rainfall may also be contained within the data. Along with the rainfall gradient, also the beginning of the rainy season is expected to occur later in the northern parts due to the north-south rainfall gradient of the inter-tropical zone of convergence.

Irrespectively of these problems, the GCPG data set was the only rainfall data available and it was consequently used, not to estimate rainfall at any given date, but rather to compare with information obtained through interviews with pastoralists in Ferlo about the different seasons. The results of these interviews are described in detail in Adriansen (2002) and here only the findings concerning the seasons are discussed.

The third data source was GPS measurements collected by Birame. The GPS in use was a GARMIN 12 XL. It provided UTM co-ordinates, date, and time for each measurement. Here, the data and the data collection protocol will be described briefly (for further detail, please refer to Adriansen and Nielsen (2002)).

Starting October 1997 and ending in October 2000, Birame took GPS measurements of the location of his cattle one day, every week. Since Birame did not herd his cattle every day he was asked to move with his cattle one day every week to perform these measurements. Each daily record comprises approximately ten measurements taken throughout the day. The method does not include night grazing, which other studies (e.g. Ayantunde et al., 2000) have found to be important for cattle. It was too tiring for Birame to follow the cattle at night, but information on the herd's whereabouts during the night was gained through interviews. Along with the GPS recordings, Birame kept notes of each measurement; whether it was at a borehole or watering point, at a camp, etc. During transhumance periods, Birame was asked to do more frequent measurements. However, due to a higher workload during transhumance, this did not 
always happen and in many places the data set is made up of only a few recordings each day, even though the frequency of daily records is higher during these periods.

The GPS data were analysed in two ways: The first part of the analysis concerned the weekly, regularly measured movements of Birame's cattle when the camp was the point of departure. This analysis is based on the three consecutive years of data collection and constitutes the main part of the analysis.

Two parameters were extracted from each day's measurements:

1. The total distance travelled by the cattle (hereafter called the distance). This distance was calculated as the sum of the Euclidian distances between all the points in one day's measurements.

2. The furthest distance from the camp (hereafter called the range). This distance was calculated as the simple Euclidian distance between Belel Nelbi and all the points measured on a given day. The largest distance was chosen.

From these two parameters a monthly average range from Belel Nelbi and the average walking distance of the cattle was calculated. Thus, for each month in the 3 years investigated, the average distance travelled by the cattle and the maximum range from the camp was calculated.

In the second part of the analysis, Birame's transhumance periods are described in more detail. However, due to the rather sporadic nature of data acquisition during these periods, no attempts to quantify movements during transhumance are made. Rather, each transhumance episode is described in detail, based on the existing data and on Birame's notes.

The final data source was questionnaires, qualitative interviews, and participatory information in Birame's camp, Belel Nelbi. The questionnaire was similar to a survey with 74 pastoralists carried out in another pastoral unit, Tessekre, in the northern part of Ferlo. A comparison of Birame's answers and the answers from Tessekre reveals that Birame's use of mobility expressed verbally - is representative for the pastoralists in Ferlo. A more in-depth analysis of this can be found in Adriansen (2002).

\section{Results}

The results will therefore be organised with respect to the two types of mobility mentioned above: daily mobility with the camp as the base, and transhumance where a temporary camp is built elsewhere. First, however, an overview of seasons and rainfall is provided, then follows the daily mobility patterns, and finally transhumance episodes are analysed.

\section{Seasons and rainfall}

According to the pastoralists, a year can be divided into the following seasons:
1. The rainy season (Ndungu) from June to August

2. The dry season from September to May, which is further divided into

a. The cold dry-season (Dabudé) from September to December

b. The hot dry-season (Thiédu) from January to April

c. Near rainy-season (Cen sedlé) in May.

In Figure 2, the seasons as identified by the pastoralists are shown beneath a graph illustrating the results obtained from GCPG data set. In the graph, the data of the four pixels (see Figure 1) have been averaged over a period from 1997 to 2000. As can be seen, the results obtained from the analysis of the GCPG data corresponds very well with information from the pastoralists, despite the aggregate nature of the GCPG data.

According to Figure 2, the first rain begins in May. The pastoralists, however, call this the near rainy-season. The precipitation seen in the figure in this month can be ascribed to rainfall events occurring in the southern most parts of the large area covered by the four pixels and hence not in the pastoral area. This is followed by the rainy season from June to August. As it can be seen from the figure, the local perception of the end of the rainy season coincides with a decrease in rainfall intensity and not necessarily with a total lack of rain. The local seasons were related to rainfall intensity in all 3 years in question, only in 1998 did the decrease in rainfall intensity occur in September rather than in August.

\section{Daily mobility}

As Figure 3 shows, the majority of the GPS observations fall within the pastoral sector of Belel Nelbi - or the pastoral unit. These measurements are predominantly connected to regular daily movements, whereas the majority of observations outside the pastoral unit are related to transhumance episodes which will be discussed in more detail below.

The figure shows that 38 percent of all measurements fall within the boundary of Belel Nelbi pastoral sector, while as much as 85 percent of all the measurements are contained within the pastoral unit. The remaining 15 percent are predominantly correlated to a major transhumance episode in 1998, which took Birame to considerable distance from Belel Nelbi.

Based on the interviews, questionnaire and participatory observations, the following description of $\mathrm{Bi}$ rame's use of mobility on a daily basis could be made: The cattle are herded all year round; it used to be his son who herded the cattle, but now he has paid a herder to do it - except from the days of GPS measurements where Birame himself would accompany the herd. The cattle know the area, which means they will not get lost if they are not herded. However, they are herded to avoid theft. Birame thinks it is better for the environment to herd the cattle because otherwise they will walk and sleep all over the place and other cattle do not want 


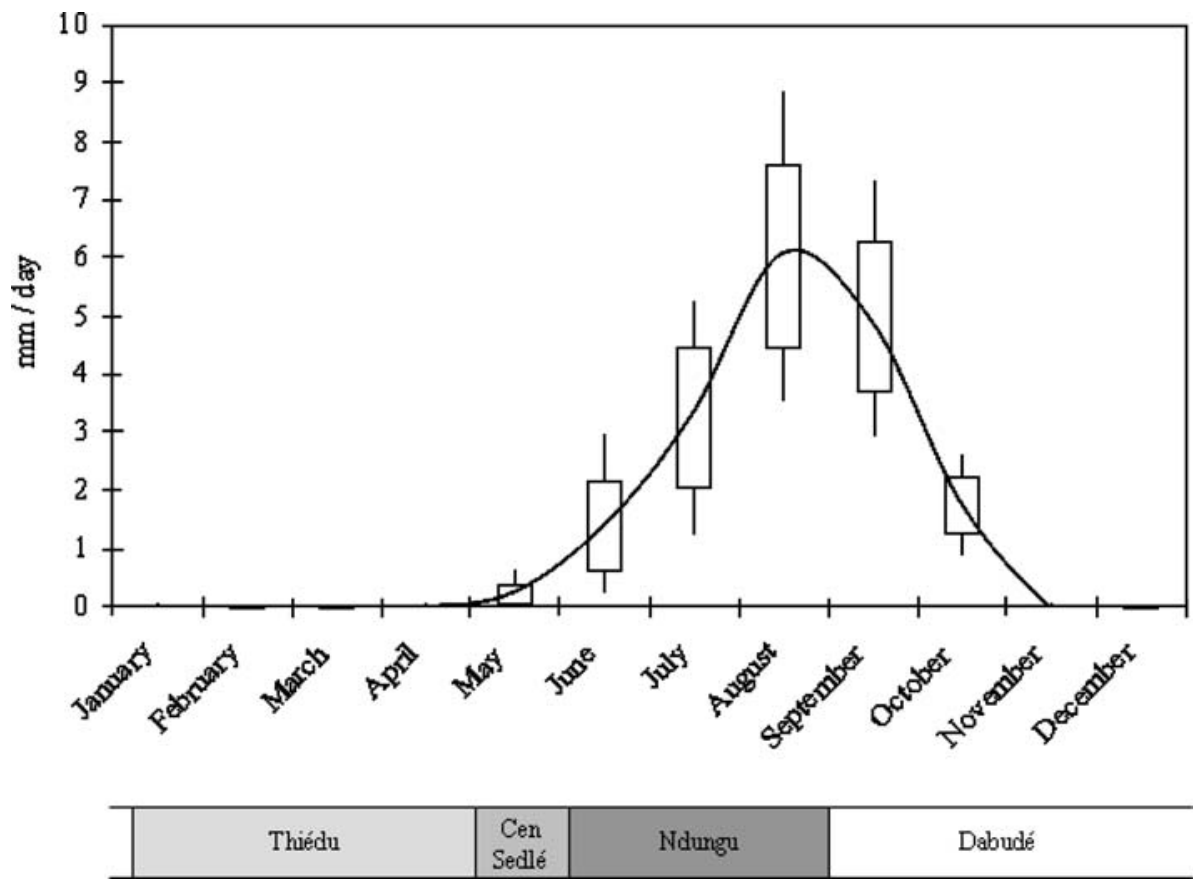

Figure 2. Yearly average rainfall intensity derived from the GCPG data set. Boxes represent 75 percent of the observations and the lines extending from the boxes indicate the absolute minimum and the absolute maximum respectively. The graph line indicates the average rainfall intensity $(\mathrm{mm} /$ day) in this period.

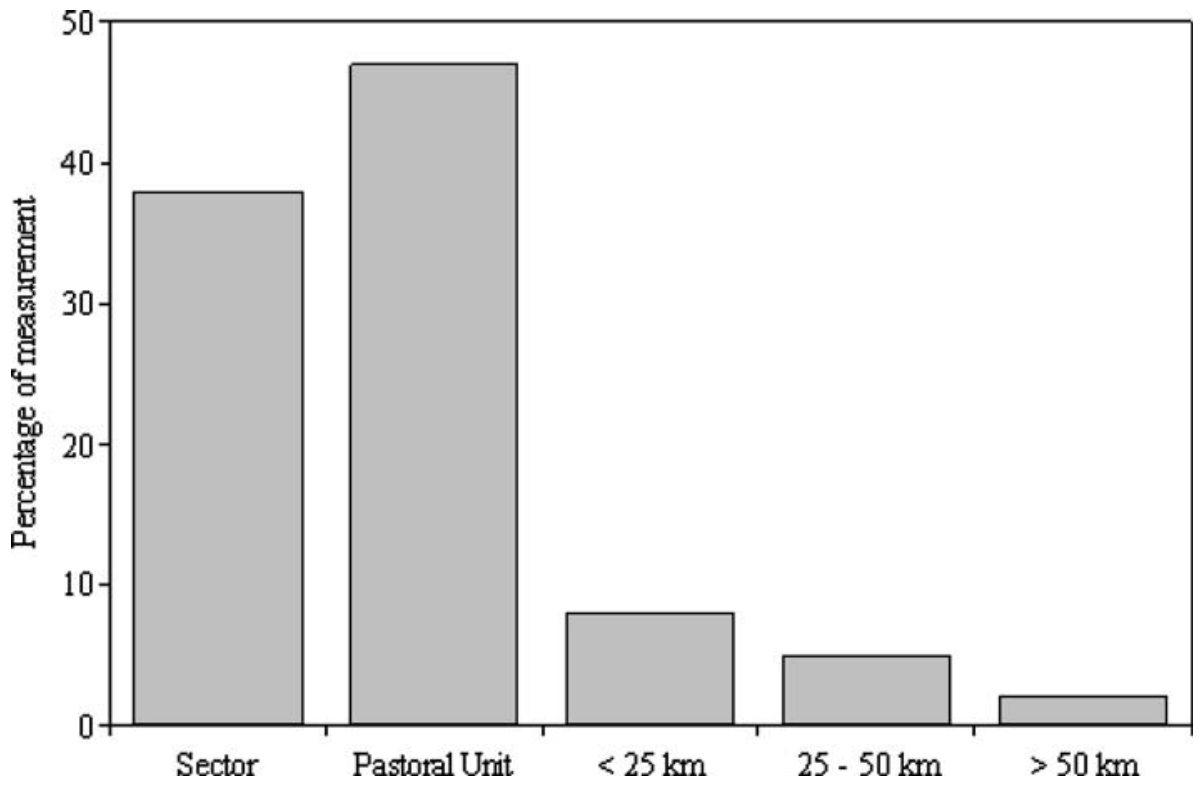

Figure 3. Location of measurements. Frequencies are calculated as percentage of total measurements. Sector refers to the pastoral sector around Belel Nelbi (where Birame's camp is located), which is part of the pastoral unit of Thiel.

to eat pasture that has been walked or slept on. On the other hand, Birame thinks the cattle prefer not to be herded, because then they can decide for themselves what to eat and when and where to sleep. Therefore, he makes sure that his cattle are herded lightly; he says 'the cattle decide for themselves'. During the night, the cattle are at a spot outside the camp called 'jofnde' - in Pulaar this means an animal 'parking space', this is not fenced and this was one of the places Birame noted in his booklet on GPS measurements. The cattle are split up into the milking herd and the rest. During the night, the milking cattle graze near the camp, and if they have not returned to the jofnde in the morning, the herder goes out to collect them. After the morning milking, the herder takes them to the antenna where they usually meet the rest of the herd. The rest of the herd leaves the jofnde at about 10:00 to 11:00 a.m. and walk slowly to the antenna where they stay until about noon and then they walk back to the camp. As long as the pasture is moist it is only necessary for the cattle to be watered every second day. This means that every other day they can graze in another direction. 
By aggregating the GPS data, an overview of Birame's daily mobility could be made: Birame uses the ponds well into the dry season, until they are dried out. In this respect, the data are easy to interpret also because Birame's notes reveal usage of ponds or boreholes. However, when it comes to the use of boreholes and the antennas extending from these the pattern becomes more complex. Usually, it is an antenna $7.5 \mathrm{~km}$ from the camp that is used, but at times it is the borehole $12 \mathrm{~km}$ away. In some cases, the cattle have passed by the antenna before going to the borehole and it is therefore most likely that there have been problems with the water supply at the antenna and sometimes this is noted in the booklet. Likewise, the use of boreholes in neighbouring pastoral units for some weeks or even months can be explained with supply problems. If there is a lack of pasture, we would expect this to be the case in the neighbouring pastoral units too, although the great spatial variability in precipitation sometimes means that one pastoral unit can have virtually no pasture while the neighbouring units have fewer problems. However, if a neighbouring borehole is used for weeks and Birame returns to Belel Nelbi before the rainy season this indicates that he has left because of water problems and not lack of pasture. Sometimes there are notes in the booklet, which can support these ideas. Hence, these types of assumptions demand a thorough knowledge of the area and the people living there.

A comprehensive impression of the mobility patterns can be obtained, if the measurements are divided into months as in Figure 4a, where the range from Belel Nelbi has been calculated for the 3 years of data. Here a clear seasonal pattern emerges; it is apparent that $\mathrm{Bi}$ rame and his cattle are very close to the camp throughout the rainy season. As the dry season progresses, a gradual increase in the range of herd movements away from the camp can be identified which seems to level off at around $8 \mathrm{~km}$.

It should be noted that the antenna, which is most frequently used, is situated approximately $7.5 \mathrm{~km}$ from Belel Nelbi. In other words; what can be seen from the figure is a pattern of mobility which is primarily based
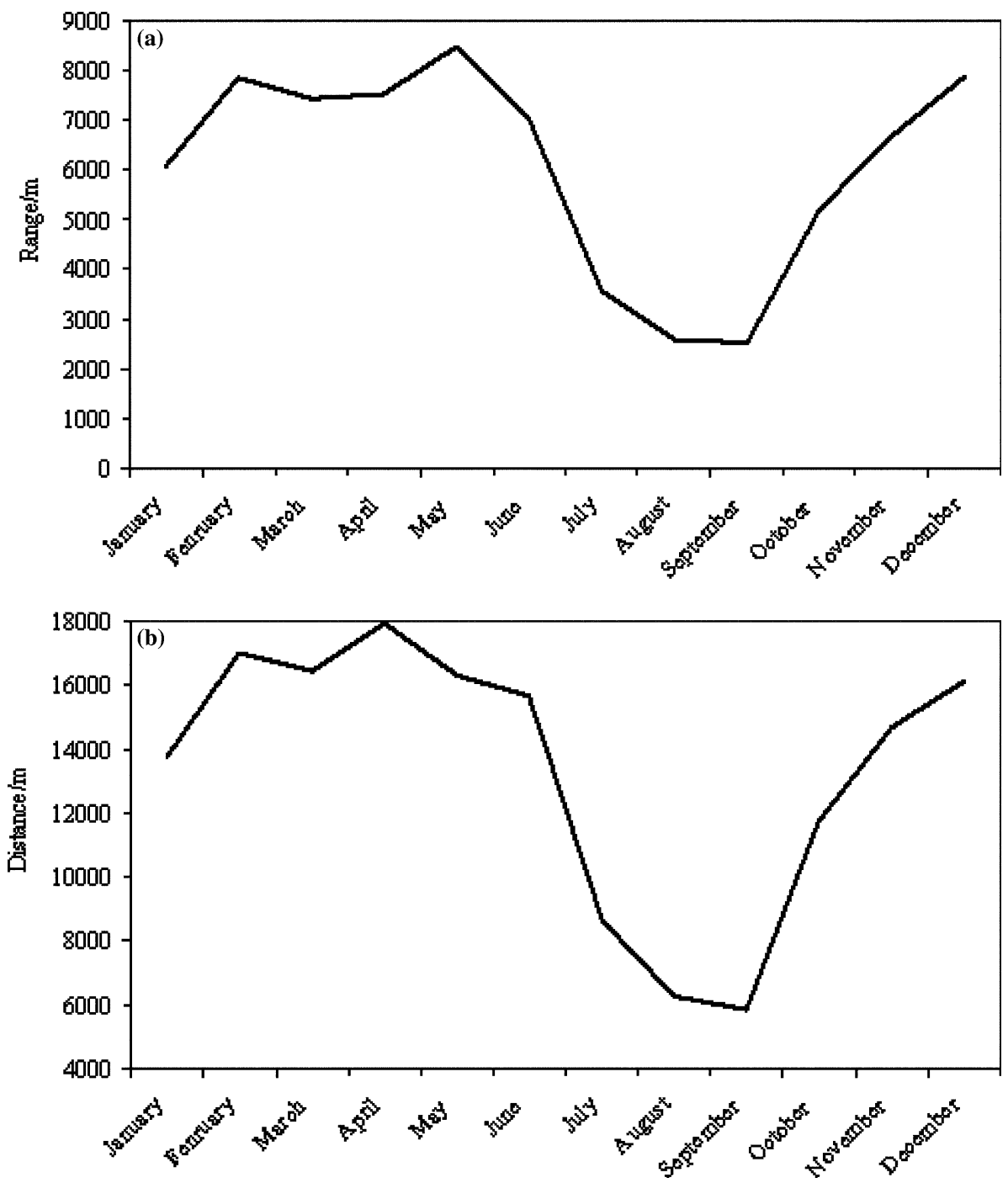

Figure 4. (a) The range from Belel Nelbi based on monthly averages for 3 years. (b) The daily distance walked based on monthly averages from 3 years. 
on the availability of water. However, some fluctuations are found in the monthly range from the camp, notably January stands out. This can be explained by the fact that in the months of January 5 out of 12 of Birame's movements do not go to the antenna, but are smaller trips in the opposite direction. He explained that when the weather is still relatively cool (as in January), the cattle are watered every second day and every other day, they walk in the opposite direction to benefit from the lesser used pasture. In our data, these west-bound trips only occur in January, but according to Birame, he also does the same in December. However, our data on daily mobility from December are limited because two of Birame's three transhumance episodes occur in this month.

The clear season pattern also emerges when looking at the total walking distance of the cattle. This is illustrated in Figure 4b, where once again the data have been accumulated into a monthly average of 3 years of data. The rainy season is a period of short treks and that the average daily walking distance increases as the dry season commences. The increase is maintained until December. During the rest of the dry season, the average distance is around $17 \mathrm{~km}$. These trips are related to the location of the antenna $7.5 \mathrm{~km}$ from the camp, thus making a daily distance of approximately $15 \mathrm{~km} \mathrm{a}$ minimum.

If the two figures are compared, it is seen that in the hot dry season (thiédu) there are various fluctuations in distance and length. This illustrates the trade-off between energy spent on getting water and pasture and the quality and amount of these resources. This trade off varies from one month to another and from year to year. For instance it is seen that the distance of the trips start to decrease in May (Figure 4b), which is earlier than would be expected if only the timing of the rains are concerned (see Figure 2). Birame characterises this period as a difficult time where the cattle are waiting for the rain. This means that the daily pattern is changed in order to make the cattle less exhausted.

From the onset of the dry season, Birame gradually increases the daily range of the trips as seen in Figure 4a. Weekly based analysis of the data reveals that the range is closely correlated to the time passed since the onset of the dry season $\left(r^{2}=0.76, n=10, \alpha<0.05\right)$, which is translated into the simple statement that the cattle's daily range to a reasonably high degree of certainty can be ascribed to the progression of the dry season. This close correlation between the two parameters apparently breaks down around the end of December where a maximum range from the village is reached and the cattle begin a more stable walking pattern (see also Adriansen and Nielsen, 2002). Similarly, there is a correlation between the distance the cattle walk every day and the progression of the dry season (see Figure 4b). Although this trend is less pronounced than for the range $\left(r^{2}=0.32, n=10, \alpha<0.16\right)$ the same general pattern is clearly observed in the two graphs.

In addition to analysing the distance and range of daily movements, we have analysed the spatial pattern with special reference to the use of water. As mentioned, water comes from two main sources: ponds and the antenna/borehole. Ponds are available from a few weeks into the rainy season (i.e. usually the middle of June) until around November. Both the antenna and the borehole are located east of Belel Nelbi (the borehole to the south-east). By looking at the percentage of eastbound movements, we therefore get an indication from the importance of these water outlets. In Figure 5, the monthly movements are illustrated with respect to their 'eastbound degree'. As such, there is no indication whether the move was to the north or south, but merely east or west. Here it can be seen that the treks of the hot dry season (Thiédu) are predominantly towards the east,

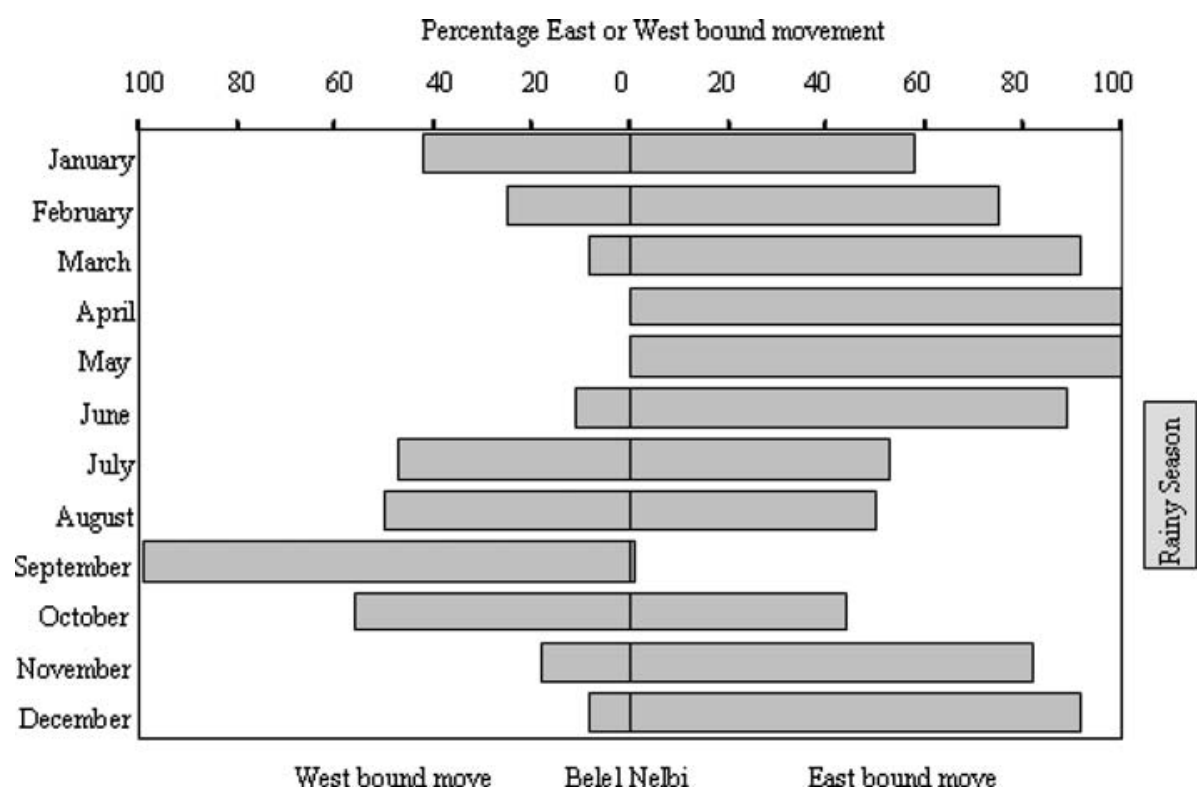

Figure 5. The frequency of east or west-bound moves. The figure shows the percentage of movements based on monthly averages from 3 years. 
which is also the direction to the antenna, while the treks of the late dry season (Cen Sedlé) and the start of the rainy season are more varied and in September practically only to the west. In the rainy season, pasture is relatively abundant and water is also present in the local ponds and the moves towards the antenna and other water outlets are not necessary.

\section{Transhumance movements}

As mentioned before, the GPS data from the transhumance episodes are scanty and cannot be analysed in the same way as the daily movements. In order to be able to analyse the whereabouts during transhumance, the interviews with Birame and his notes have been invaluable for understanding changes in the overall picture. Also, information from the GIS on location of ponds, watering points has been used. The three transhumance episodes, which we can detect in the data set, have a duration of more 40-55 days and involve the construction of a camp in a new place from which a new pattern of daily migrations emerge. Two of these episodes do not amount to much at first glance, because they are not far away from Belel Nelbi, but both of them last about 6 weeks.

Birame was away on one long transhumance during the time of the GPS-experiment; this is called episode 1. This was in 1998. He left before the first rain in Belel Nelbi, somewhere between June 23-28 and was back August 19. He did not take measurements every day from the time he left the camp. The first day from where we have measurements was June 28 . He took three measurements in the evening, and the range from Belel Nelbi was $38 \mathrm{~km}$ at the first GPS measurement that day. The following 10 days, he gradually moved further away, spending a few nights at the same temporary camp making round trips of approximately $8 \mathrm{~km}$ during the daily movements. The daily distance during days of movement to a new camp was up to $15 \mathrm{~km}$. In the evening of July 8 , he arrived at a place that remained the point of departure during the rest of the time he was there. We therefore assume that he set up a temporary camp there. The place was next to a pond $78 \mathrm{~km}$ from Belel Nelbi. Birame's notes indicate that the rain had started, hence he could benefit from the water in the pond and the new pasture. During the following 5 weeks, he made measurements every Monday, as agreed. During these trips the cattle walked an average of $13 \mathrm{~km}$ per day. This means these trips are shorter than most trips made with Belel Nelbi as the point of departure. On the way back, Birame made measurements every day from the time he left the temporary camp until he was back in Belel Nelbi. These measurements show that the herd walked about $25 \mathrm{~km}$ per day, except one day where they only made $5 \mathrm{~km}$.

Episode 2 occurred in November 1998, at the beginning of the dry season. The herd left Belel Nelbi on November 18 and stayed away for 6 weeks. The first day they walked $16-\mathrm{km}$ north-east, here Birame set up a camp where they stayed for the whole period. For the first 3 weeks, they benefited from the water in a pond another $7 \mathrm{~km}$ to the east. After this had dried out, they stayed in the camp but started walking in the opposite direction to get water from an antenna. This is actually the same antenna that they use when they stay in Belel Nelbi; therefore it is reasonable to assume that they stayed away because the pasture was good where they were. During the whole transhumance episode, they stayed within the pastoral unit, and maintained an average daily distance of $17 \mathrm{~km}$.

Episode 3 is similar to episode 2 and took place the year after, in 1999. This time they left about November 8 and returned about 6 weeks later. The pattern is similar to the one the year before. A camp was set up $9.5 \mathrm{~km}$ north-east from Belel Nelbi, and in the period November 13-29 the pattern was the same: a return trip from this camp to a pond about $6 \mathrm{~km}$ away: The average distance walked by the cattle in this period was $10 \mathrm{~km}$. Between November 30 and December 6, Birame began to take the cattle to the borehole in Thiel because the pond dried out. In this period the cattle walked an average of $16 \mathrm{~km}$.

\section{Discussion}

The data show that although Birame - or rather his cattle - are quite mobile, the major part of the movements take place within the pastoral unit, especially in the so-called sector with Birame's camp and the neighbouring sector where the antenna is located.

In Figure 6, the spatial distribution of movements as well as the density of the observations are shown. The first impression is the pronounced east-west orientation of the measurements. If compared with Figure 5, it is seen that the high density of measurements to the west of Belel Nelbi are almost exclusively connected to late dry season or early rainy season movements, while the eastbound moves are predominantly going to the antenna and other water outlets. Two groups of observations stand out furthest to the east; these two areas are ponds where Birame goes with his cattle during transhumance. The observations visible in the lower portion of the Figure 6, originate from one of Birame's transhumance periods. By far the highest density of observations are found close to the central borehole on the border between two pastoral sectors and these clearly

Figure 6. Top part of the figure shows the spatial density of observations performed by Birame from 1997 to 2000. Densities are calculated on the basis of the furthest daily range of the measurements within a $5 \mathrm{~km}$ search radius. Bottom part of the figure illustrates the vegetation index NDVI (Normalized Difference Vegetation Index) obtained from the NOAA AVHRR sensor for July 1998 - coinciding with the transhumance period visible in the upper part of the figure. Colorations in the lower part of the figure range from white (low vegetation index values) to dark grey (high vegetation index values). The pastoral sector and unit divisions are included in the figure as well as pond and borehole locations. 

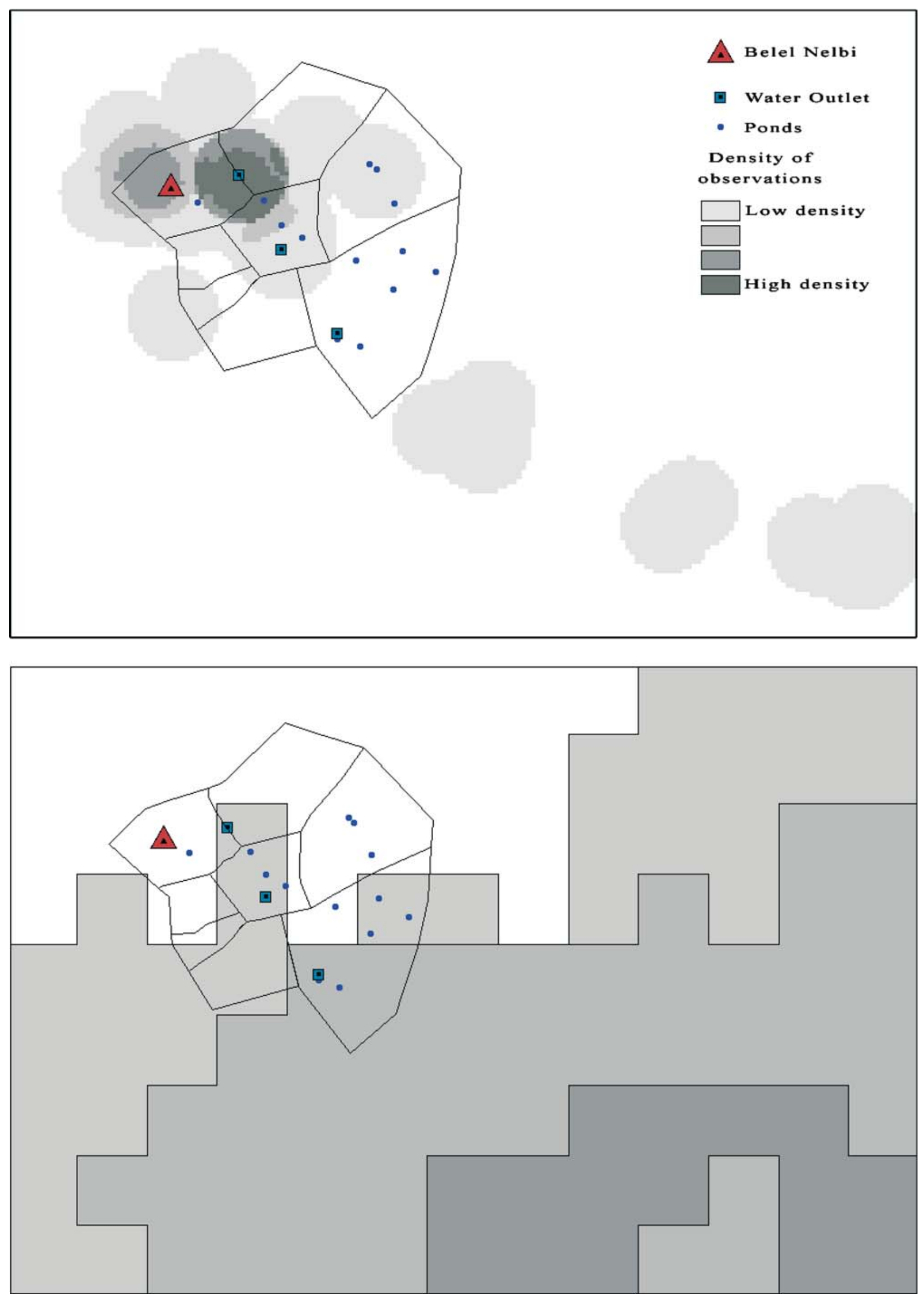
indicate that the major parameter controlling Birame's use of mobility is access to water.

It could be argued that it is rational for Birame to go on transhumance because this means that the cattle walk less. However, one should bear in mind that the cattle are herded during the transhumance, which means that the workload is greater. Also, it is important to bear in mind that the average day trip in Belel Nelbi during and just after the rainy season is around $7 \mathrm{~km}$. In this perspective, transhumance seems irrational; the cattle walk further and the workload is greater during transhumance compared to staying at home. Birame explained that the cattle benefit from the new grasses germinating during and after the rainy season.

The main benefit of GPS data is that they provide spatial information that can be used in combination with other spatial data. When the location of ponds and boreholes is known analysis of movements in relation to access to water is possible. Further, there is a potential of integrating GPS data with satellite imagery, which by nature is geo-referenced. An example of this can be seen in the lower part of Figure 6. Here a map of the (NOAA AVHRR) satellite derived vegetation index NDVI can be seen. Even though NDVI is not directly linked to the amount of biomass, it is generally agreed that NDVI (or rather; the yearly integrated NDVI) can be used as a proxy for the biomass production. As indicated by Figure 6, the transhumance episode of Birame is of a general direction towards higher biomass amounts. This shows the potential of integrating GPS data, GIS data layers and satellite derived information about surface cover to achieve a better understanding of the mobility and natural resource nexus.

Due to the way of data collection, we can only make a rough estimate of the average yearly distance walked. This is $5000 \mathrm{~km}$. In this calculation, we have accounted

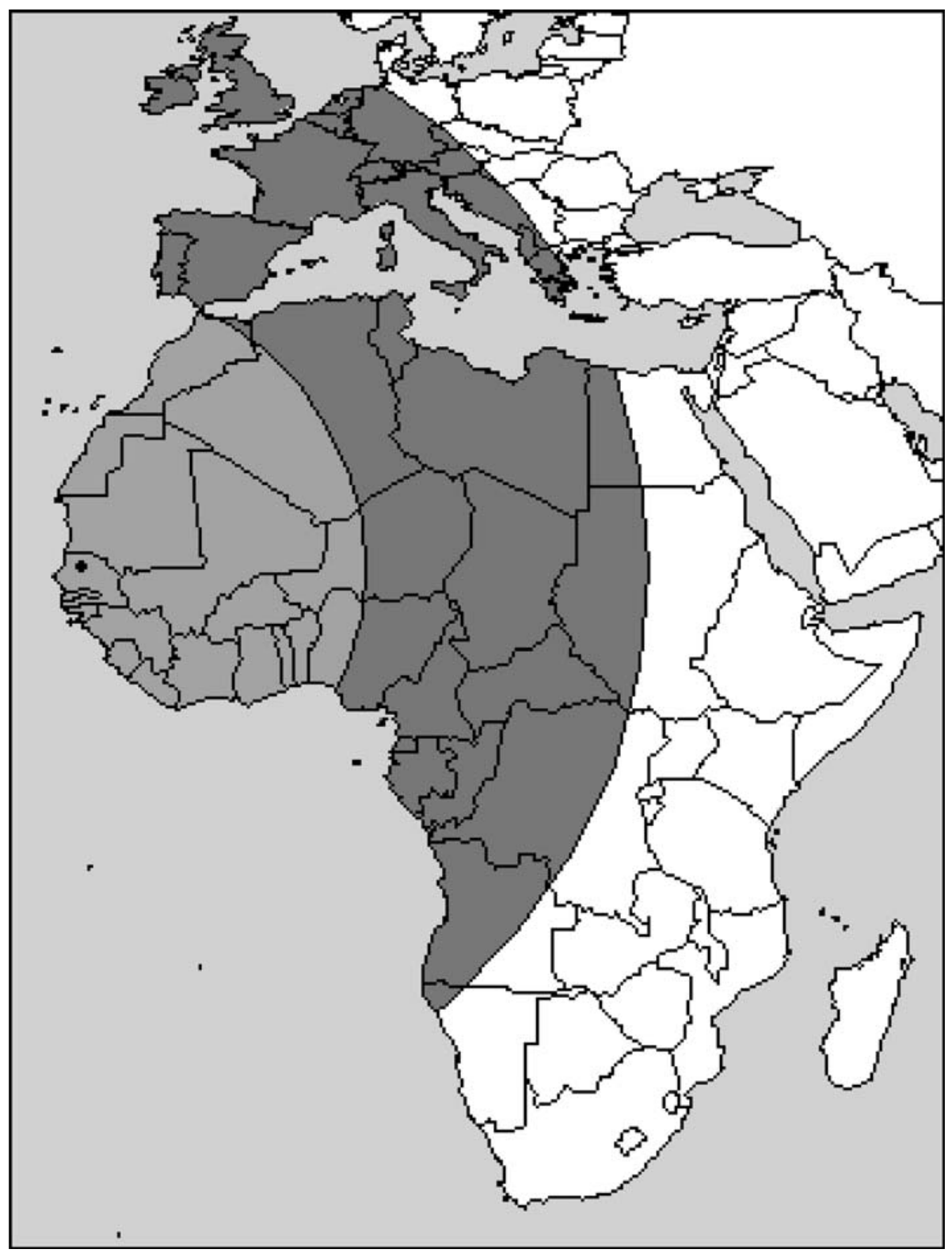

Figure 7. The potential area that Birame's cattle could reach within a year if they did not return to the camp. The light grey circle indicates a return trip, while the dark grey circle shows a one-way trip. Belel Nelbi is shown by the black dot. 
for Birame's transhumance episodes. Hence, due to the large scale transhumance episode in the rainy season of 1998 the yearly mobility this year is approximately $5800 \mathrm{~km}$, while it is approximately 4700 in 1999 where only a smaller transhumance episode occurred. However, due to insufficient data for 2000 (data collection ended in October), it has not been possible to calculate the total yearly distance covered by Birame's cattle.

\section{Concluding remarks}

The aim of this paper was to show the potential of GPS data for quantification and mapping of pastoral mobility. The data were provided by a herder using a handheld GPS. Even though a GPS collar would provide more accurate data on the location of the cattle especially because night grazing could be included, the use of a herder with a GPS and a notebook certainly has a number of advantages not only in terms of understanding the use of mobility, but the herder can also provide valuable information such as on the drying out of ponds and vegetation status.

The paper shows that GPS technology is useful for studying pastoralist's movements of their herds in the landscape because accurate and consistent data on the use of space can be obtained. However, GPS data can also provide information for understanding more abstract uses of space and pastoralists formation of space into place when combined with qualitative interviews with the pastoralists. The construction of place among pastoralists in the Ferlo has been beyond the scope of this paper, but has been discussed in detail by Adriansen, 2002.

The GPS data show that the daily movements actually contribute a large part of the total distance walked per year. By providing not only quantitative but also spatial information, GPS data allowed us to characterise different mobility patterns and related them to resource availability. This showed the remarkable difference in mobility patterns especially in and just after the rainy season.

A thorough understanding of the whereabouts of livestock is of importance not only for understanding the grazing-vegetation nexus but also from an animal production point of view. However, while the GPS data provide valuable information on how far and where pastoralists or herds walk, these data do not tell us why they walk. Hence, in order to understand the use of mobility, interviews with the pastoralists responsible for the herds are valuable.

The aim of this paper was to show a contribution of geography to the study of pastoral mobility. While recent discussions of pastoral mobility have pointed to the fact that pastoralists become more sedentary, this paper shows that Birame might be settling down, but his cattle are not. This is illustrated in Figure 7 where the total walking distance of Birame's cattle has been superimposed on a subset of a world map. Here it is seen that Birame's cattle could make a yearly round-trip to Gibraltar or alternatively a one-way trip to Hamburg. However, this is not Birame's choice and instead he relies on local resources and utilizes the mobility of his herd in order to maintain a fairly settled lifestyle.

\section{References}

Adriansen H.K., 2002: A Fulani without cattle is like a woman without jewellery: a study of pastoralists in Ferlo, Senegal. Geographica Hafniensia, A11, Copenhagen.

Adriansen, H.K., 2006: Continuity and change in pastoral livelihoods of Senegalese Fulani. Agriculture and Human Values (forthcoming).

Adriansen H.K. and Nielsen T.T., 2002: Going where the grass is greener: on the study of pastoral mobility in Ferlo, Senegal. Human Ecology 30(2): 215-226.

Alissoutin, R.L., 1997: Pond management in the Podor department, Senegal. IIED Drylands Programme, Issue Paper 72.

Ayantunde A.A., Williams T.O., Udo H.M.J., Fernández-Rivera S., Hiernaux P. and Keulen H.van, 2000: Herders' perceptions, practice, and problems of night grazing in the Sahel: case studies from Niger. Human Ecology 28(1): 109-130.

Ba C., 1986: Les Peuls du Sénégal. Etude géographique. Les Nouvelles Editions Africaines, Dakar.

Barral H., 1982: Le Ferlo des forages. ORSTOM, Dakar.

Basset T.J., 1986: Fulani herd movements. The Geographical Review 76(3): 233-248.

Behnke R.H. Scoones I. Kerven C. (eds.), 1993: Range Ecology at Disequilibrium: New Models of Natural Variability and Pastoral Adaptation in African Savannas. Overseas Development Institute, Nottingham.

Bernus, E., 1979: Le contrôle du milieu naturel et du troupeau par les éleveurs touaregs sahéliens. In: L'Equipe écologie et anthropologie des sociétés pastorales (eds.), Production pastorale et société Pastoral production and society. Proceedings of the international meeting on nomadic pastoralism, Paris 1-3 December 1976. Cambridge University Press, Cambridge, 67-74.

Burnham, P., 1979: Spatial mobility and political centralization in pastoral societies. In: L'Equipe écologie et anthropologie des sociétés pastorales (eds.), Production pastorale et société - Pastoral production and society. Proceedings of the international meeting on nomadic pastoralism, Paris 1-3 December 1976. pp. 349-360. Cambridge University Press, Cambridge.

Coppolillo P.B., 2000: The landscape ecology of pastoral herding: Spatial analysis of land use and livestock production in East Africa. Human Ecology 28(4): 527-560.

Dupire M., 1975: Exploitation du sol, communautés résidentielles et organisation lignagère des pasteurs WoDaaBe (Niger). In: Monod T. (ed.), Pastoralism in Tropical Africa. Studies presented and discussed at the 13th international African seminar, Niamey, December 1972. International African Institute by Oxford University Press, Oxford, 322-338.

Dyson-Hudson R. and Dyson-Hudson N., 1980: Nomadic pastoralism. Annual Review of Anthropology 9: 15-61.

Ellis J.E. and Swift D.M., 1988: Stability of African pastoral ecosystems: alternative paradigms and implications for development. Journal of Range Management 41: 450-459.

Ellis J.E., 1995: Climate variability and complex ecosystem dynamics: implications for pastoral development. In: Scoones I. (ed.), Living with Uncertainty: New Directions in Pastoral Development in Africa. pp. 37-46. Intermediate Technology Publications, Exeter.

Ellis J.E., Cougenour M.B. and Swift D.M., 1993: Climate variability, ecosystem stability, and the implications for range and livestock development. In: Behnke R.H., Scoones I. and Kerven C. (eds.), Range Ecology at Disequilibrium: New Models of Natural Variability and Pastoral Adaptation in African Savannas. pp. 31-41. Overseas Development Institute, Nottingham.

Equipe ECOSSEN 1997: Crises de l'environnement et dynamique des espaces ruraux du nord-ouest Sénégalais. Rapport technique à 3 ans. Université Cheikh Anta Diop, IFAN, Laboratoire de Géographie; 
Project ECOSSEN, subventionné par le CRDI, Ottawa, Canada; Université de Sherbrooke, CARTEL.

Fitzsimmons M., 2004: Space and substance in geography. In: Cloke P., Crang P. and Goodwin M. (eds.), Envisioning Human Geographies. pp. 30-47. Arnold, Malta.

Freudenberger M.S. and Freudenberger K.S., 1993: Pastoralism in Peril: Pressures on Grazing Land in Senegal. IIED Drylands Programme, Pastoral Land Tenure Series, No. 4

GPCP (2001): http://eosdata.gsfc.nasa.gov/CAMPAIGN_DOCS FTP_SITE/INT_DIS/.

Grenier P., 1987: Les problèmes energitiques du Ferlo (Sahel sénégalais). In: di Meo G., Grenier P., Guerrero R. and Jambes J.P. (eds.), Energie et espace au Sénégal. pp. 63-162. Travaux et documents de géographie tropicale, CEGET, C.N.R.S., Talence Cedex.

Irons W., 1968: The Turkmen nomads. Natural History 77: 44-51.

Johnson D.L., 1969: The Nature of Nomadism - A Comparative Study of Pastoral Migration in South-Western Asia and Northern Africa. Research Paper No. 118, Department of Geography, University of Chicago, Chicago.

Juul K., 1999: Tubes, tenure and turbulence; the effects of drought related migration on tenure issues and resource management in Northern Senegal. Ph.D. Dissertation, Roskilde University, Denmark.

Lane S.N., 2001: Constructive comments on D Massey 'Space-time, "science" and the relationship between physical geography and human geography'. Transactions of the Institute of British Geographers NS 26: 243-256.

Niamir-Fuller M., 1998: The resilience of pastoral herding in Sahelian Africa. In: Berkes F., Folke C. and Colding J. (eds.), Linking Social and Ecological Systems: Management Practices and Social Mechanisms for Building Resilience. pp. 250-284. Cambridge University Press, Cambridge.

Niamir-Fuller M.(eds.) 1999: Managing Mobility in African Rangelands: The Legitimization of Transhumance. IT Publications, Exeter.

Pamo E.T., 1998: Herders and wildgame behaviour as a strategy against desertification in northern Cameroon. Journal of Arid Environments 39: 179-190.
Roe E., Huntsinger L. and Labnow K., 1998: High reliability pastoralism. Journal of Arid Environments 39: 39-55.

Santoire C., 1983: Raison pastorale et développement: Les société Peuls face au aménagement. Travaux et documents de l'ORSTOM no. 166. ORSTOM, Dakar.

Schareika N., 2001: Environmental knowledge and pastoral migration among the Wodaabe of South-Eastern Niger. Nomadic Peoples NS 5(1): 65-88.

Schlecht E., Hülsebusch C., Mahler F. and Becker K., 2004: The use of differentially corrected global positioning system to monitor activities of cattle at pasture. Applied Animal Behavior Science 85: 185202.

Sickel H., Ihse M., Norderhaug A. and Sickel M.A.K., 2004: How to monitor semi-natural key habitats in relation to grazing preferences of cattle in mountain summer farming area. An aerial photo and GPS method study. Landscape and Urban Planning 67: 67-77.

Smith N., 2004: Space and substance in geography. In: Cloke P., Crang P., and Goodwin M. (eds.), Envisioning Human Geographies. pp. 11-29. Arnold, Malta.

Stenning D.J., 1957: Transhumance, migratory drift, migration; patterns of pastoral Fulani nomadism. Journal of the Royal Anthropological Institute of Great Britain and Ireland 87(1): 57-73.

Taylor P.J., 1999: Places, spaces and Macy's: place-space tensions in the political geography of modernities. Progress in Human Geography 23(1): 7-26.

Thébaud B. and Batterbury S., 2001: Sahel pastoralists: opportunism, struggle, conflict and negotiation: A case study from Niger. Global Environmental Change 11: 69-78.

Touré O., 1990: Where Herders Don't Herd Anymore: Experience from the Ferlo, Northern Senegal. IIED Drylands Programme, Issue Paper, No. 22.

Turner M.D. and Hiernaux P., 2002: The use of herders' accounts to map livestock activities across agropastoral landscapes in SemiArid Africa. Landscape Ecology 17: 367-385.

Unwin T., 2000: A waste of space? Towards a critique of the social production of space.... Transactions of the Institute of British Geographers NS 25: 11-29. 